\title{
Instrumentation and performance evaluation of the XRS on SELENE orbiter
}

\author{
K. Shirai ${ }^{1}$, T. Okada ${ }^{1}$, Y. Yamamoto ${ }^{1}$, T. Arai $^{1}$, K. Ogawa ${ }^{1,2}$, H. Shiraishi ${ }^{1}$, \\ M. Iwasaki ${ }^{1,2}$, M. Arakawa ${ }^{3}$, M. Grande ${ }^{4}$, and M. Kato ${ }^{1,2}$ \\ ${ }^{1}$ Institute of Space and Astronautical Science, Japan Aerospace Exploration Agency, 3-1-1 Yoshinodai, Sagamihara, Kanagawa 229-8510, Japan \\ ${ }^{2}$ Department of Earth and Planetary Sciences, Tokyo Institute of Technology, 2-12-1 Ookayama, Tokyo 152-8551, Japan \\ ${ }^{3}$ Graduate School of Enviromental Studies, Nagoya University, Furo-cho, Chikusa-ku, Nagoya 464-8602, Japan \\ ${ }^{4}$ Institute of Mathematical and Physical Sciences, University of Wales, Aberystwyth, Ceredigion, SY23 3BZ, Wales, UK
}

(Received May 8, 2007; Revised October 15, 2007; Accepted November 10, 2007; Online published April 9, 2008)

\begin{abstract}
The X-ray fluorescence spectrometer (XRS) on board Japanese lunar polar orbiter SELENE (Kaguya) will provide global distribution of major elemental composition on the lunar surface in energy range of characteristic $\mathrm{K}-\alpha$ x-ray line emission for $\mathrm{Mg}, \mathrm{Al}, \mathrm{Si}, \mathrm{Ca}, \mathrm{Ti}$, and $\mathrm{Fe}$. These measurements will contribute to research of lunar origin and its evolution. The XRS shows a good energy resolution within $200 \mathrm{eV}$ at $5.9 \mathrm{keV}$ relying on charge coupled device (CCD) as photon energy dispersive detector. Total collective area of $100 \mathrm{~cm}^{2}$ for main detector facing the lunar surface is composed of 16 CCD chips. Instrumentation of the XRS and its performance evaluated in laboratory are presented.
\end{abstract}

Key words: X-ray fluorescent spectrometry, global mapping, Moon, charge coupled device.

\section{Introduction}

The X-ray fluorescence spectrometer (XRS) is one of 14 scientific instruments on-board SELENE (SELenological and ENgineering Explorer) mission (Sasaki et al., 2003; Kato et al., 2007), launched to the Moon in the summer of 2007 by H-IIA. It has been developed to observe characteristic $\mathrm{X}$-rays emitting from the lunar surface to provide global mapping of major elemental composition (Okada et al., 1999, 2002; Yamamoto et al., 2007). The XRS is a CCDbased $\mathrm{x}$-ray fluorescence spectrometer utilizing the heritage of the x-ray spectrometer on-board the Japanese asteroid mission Hayabusa (Okada et al., 2000, 2006a, 2006b).

The Apollo 15 and 16 missions carried x-ray spectrometer based on sealed proportional counter and performed lunar remote x-ray fluorescence spectroscopy (Clark et al., 1978; Clark and Hawke, 1981; Bielefeled et al., 1977; Adler et al., 1972). Although its coverage was limited in the near-side equatorial regions, up to $\sim 9 \%$ of the whole lunar surface, Apollo 15 and 16's x-ray measurements of $\mathrm{Mg} / \mathrm{Si}$ and $\mathrm{Al} / \mathrm{Si}$ ratios have proven the strength of XRF in ability to remotely measure elemental abundances such as $\mathrm{Mg}, \mathrm{Al}$, and $\mathrm{Si}$ of atmosphere-free planetary surfaces (Adler and Trombka, 1977).

More recently the European Space Agency's SMART-1 mission carried the Demonstration of a Compact Imaging X-ray Spectrometer (D-CIXS), which also performed X-ray spectroscopic remote observation of lunar surface (Grande et al., 2007). The D-CIXS instrument uses swept charge device (SCD) array as a main detector (Grande, 2001). The SCD $\mathrm{x}$-ray detector is a novel architecture based on charge

Copyright (c) The Society of Geomagnetism and Earth, Planetary and Space Sciences (SGEPSS); The Seismological Society of Japan; The Volcanological Society of Japan; The Geodetic Society of Japan; The Japanese Society for Planetary Sciences; TERRAPUB. coupled device (CCD) technology which has virtue of providing superior $\mathrm{X}$-ray detection and spectroscopic measurements capabilities as CCDs. The D-CIXS's initial observation over Mare Crisium and nearby highland area took place during occurrence of M-class solar flare (Kellett et al., 2006). The spectra obtained during this period are reported to indicate the first unambiguous detection of Calcium from the lunar surface (Grande et al., 2007).

As the strength of the remote XRF technique in ability of quantitative and qualitative measurement for elemental abundances such as $\mathrm{Mg}, \mathrm{Al}$, and $\mathrm{Si}$, future planned lunar explorer missions such as Chinese Chang'e-1 (Sun et al., 2005) and Indian Chandrajaan-1 (Bhandari, 2005) will also carry XRF spectrometers as one of its core scientific payloads. Apart from lunar observation, Near-Earth Asteroid Rendezvous (NEAR)-Shoemaker mission has observed Asteroid 433 Eros (Trombka et al., 2000) and coming Messenger and Bepi Colombo Mercury missions also carry x-ray spectrometers (Gold et al., 2001; Benkhoff, 2007; Grande et al., 2001).

The XRS on-board SELENE aims its primary goal in global mapping of major elemental abundance of the lunar surface through remote XRF spectroscopic technique. During quiescent solar conditions, the solar output of higher energies are relatively low, insignificant to measure the higher energies of heavier fluorescent lines. Under these conditions only the lighter elements such as $\mathrm{Mg}, \mathrm{Al}$, and $\mathrm{Si}$ lines are excited and can be measured. Both the lighter and the heavier elements such as $\mathrm{Ca}, \mathrm{Ti}$, and $\mathrm{Fe}$ will be observable when the sun is active. The distance to the fluorescing target will be measured in $100 \mathrm{~km}$ rather than centimeters encountered in the laboratory $\mathrm{x}$-ray experiments. In order to measure fluorescent lines with great accuracy and to obtain measurements with high spatial resolution, the detector has a large collection area of $100 \mathrm{~cm}^{2}$ and ultra-thin beryllium 
Table 1. Specifications and consumed resources of the XRS instrument.

\begin{tabular}{cccc}
\hline & XRF-A & SOL-B & SOL-C \\
\hline Detector & Si-CCD $\times 16$ chips & Si-PIN photo-diode $\times 2$ chips & Si-CCD + glass plate $($ Table 2) \\
Effective area & $100 \mathrm{~cm}^{2}$ & pinhole & $6 \mathrm{~cm}^{2}$ \\
FOV & $12 \times 12$ degrees & $x:-80 \sim+80, y:-80 \sim+5$ degrees & $x:-80 \sim+80, y:-80 \sim+5$ degrees \\
Energy coverage & $1 \sim 10 \mathrm{keV}$ & $1 \sim 20 \mathrm{keV}$ & $1 \sim 10 \mathrm{keV}$ \\
\hline Other resources: & & \\
Total mass & $20.67 \mathrm{~kg}$ (XRF-A: $8.73 \mathrm{~kg}$, SOL-BC: $4.00 \mathrm{~kg}$, XRS-E: $7.94 \mathrm{~kg})$ & \\
Power consumption & $46.3 \mathrm{~W}$ for nominal observation, $58.6 \mathrm{~W}$ at maximum \\
Allowed bus-rate & $32 \mathrm{kbps}$ while at lunar day side, $3.2 \mathrm{kbps}$ while at lunar night side &
\end{tabular}

optical light-tight window. The detection system, an array of CCD chips, has relatively high energy resolution achievable with passive cooling.

\section{The XRS Instrumentation}

The XRS consists of three components: Lunar X-ray fluorescence detector (XRF-A), Solar X-ray monitor/calibrator (SOL-B, SOL-C), and the electronic package (XRS-E) which controls the detector system.

The XRS is on-board a 3-axis stabilized spacecraft SELENE with XRF-A pointing the nadir, while SOL-B and SOL-C component is mounted on upper panel, the opposite side of the spacecraft (Kato et al., 2007; Okada et al., 2002). The specifications of the XRS detectors and the resources for the instrument are shown in Table 1, respectively and detailed characteristics are described below.

\subsection{Lunar X-ray fluorescence detector (XRF-A)}

The Lunar X-Ray Fluorescence Detector (XRF-A), main detector facing to surface of the moon, will measure $\mathrm{X}$ ray photons radiating from the lunar surface. The XRFA, mounted on the side panel of SELENE orbiter, consists from four units of CCD-based energy-dispersive detector with a passive radiator thermally connected to the CCD chips (Fig. 1).

We adopted front-illuminated, full-frame transfer type CCD (Deep-1 model) manufactured by Hamamatsu Photonics, K. K. (Miyaguchi et al., 1999), which has 1024 by 1024 effective pixels in 1-inch square size detection area packaged into three sides abuttable shape. Four of the CCD chips are arrayed 2 by 2 into a detector unit. Four of these detector units composes $100 \mathrm{~cm}^{2}$ of collective area in total with 16 CCD chips. Each detector unit is equipped with a latticed collimator, limiting the effective field of view (FOV) to $12^{\circ}$ and an ultra-thin $(5 \sim 10 \mu \mathrm{m})$ beryllium optical light-tight window in front of the CCD chip to gain high $\mathrm{x}$-ray transparency for low energy $\mathrm{x}$-ray down to around $0.7 \mathrm{keV}$. Low energy cutoff in efficiency as a whole detector system is about $1 \mathrm{keV}$ due to absorption by the surface structure of the CCD chip itself. Although each CCD chips are equipped with a thermal electric cooler, its usage is limited to tests while on the ground prior to the launch. During the observation period of the moon the radiator of $800 \mathrm{~cm}^{2}$, a kind of optical solar reflector, is thermally designed to successfully cool the CCD chips well below $-40^{\circ} \mathrm{C}$ throughout the observation except for periods when solar phase angle becomes less than $10^{\circ}$.

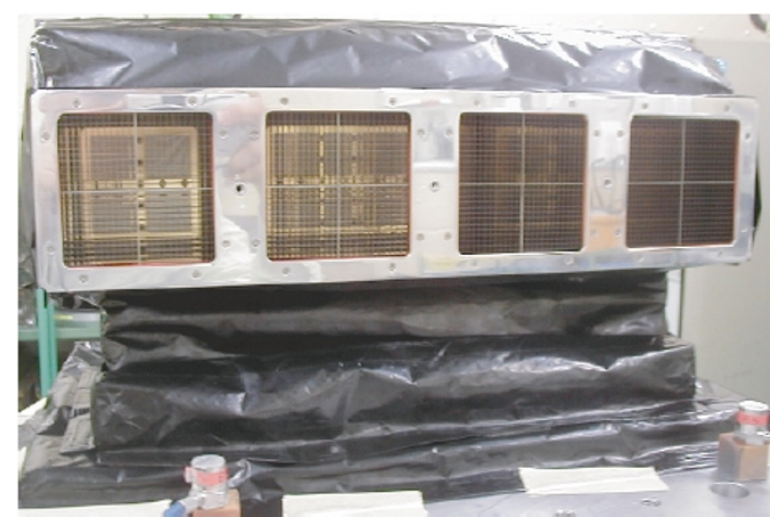

Fig. 1. Photograph of the Lunar X-ray fluorescence detector (XRF-A) is shown, viewed from the side of the latticed collimator for $16 \mathrm{CCD}$ chips. Beryllium light-tight window can be seen inside. Backside of CCD chips is thermally connected to a radiator, not seen in this figure. XRF-A is mounted on the side panel of SELENE, detector facing to the lunar surface.

\subsection{Solar x-ray monitor \& calibrator (SOL-B, SOL-C)}

In order to attain quantitative spectroscopic measurement, monitoring of primary excitation source is essentially required. This is especially important in planetary x-ray fluorescent measurements (Clark et al., 1978) while the flux of solar x-ray, major primary source radiating the lunar surface varies in energies within a short period of time. The solar $\mathrm{x}$-ray decreases its flux for more than 4 orders of magnitude in $1 \mathrm{keV}$ to $10 \mathrm{keV}$ range of $\mathrm{x}$-ray energies under quiet Sun conditions, while the decrease eases for a higher solar activity, tending to harden the solar x-ray flux.

In the case of SELENE XRS, simultaneous measurements of solar X-ray along with the lunar fluorescent X-ray measurement with XRF-A are acquired with SOL-B and SOL-C. Two Si-PIN photo-diodes (AMPTEK, XR-100T) are mounted on the SOL-B for that either one will be capable to directly observe the solar x-ray through $\phi 1 \mathrm{~mm}$ pin-hole covering -80 to +80 degree in its field of view each. The detector itself has $7 \mathrm{~mm}^{2}$ detection area and $300 \mu \mathrm{m}$ thick depletion layer, with a window shielded with 1 mil thick beryllium foil. The outputs from Si-PIN photodiode is processed and accumulated respectively by multichannel (255 channels) pulse height analyzer refreshed every 16 seconds. The SOL-C, another solar x-ray monitor, acts also as XRF calibrator. It consists of a single CCD chip and a fused sample plate whose compositions (Table 2) are 
Table 2. Compositions (wt\%) of glass plate used in SOL-C.

\begin{tabular}{cr|cc}
\hline $\mathrm{SiO}_{2}$ & 39.0 & $\mathrm{Na}_{2} \mathrm{CO}_{3}$ & 3.0 \\
$\mathrm{TiO}_{2}$ & 2.5 & $\mathrm{~K}_{2} \mathrm{CO}_{3}$ & 1.5 \\
$\mathrm{Al}_{2} \mathrm{O}_{3}$ & 16.0 & $\mathrm{P}_{2} \mathrm{O}_{5}$ & 0.0 \\
$\mathrm{Fe}_{2} \mathrm{O}_{3}$ & 12.0 & $\mathrm{MnO}_{2}$ & 1.0 \\
$\mathrm{MgO}$ & 7.0 & $\mathrm{Cr}_{2} \mathrm{O}_{3}$ & 1.0 \\
$\mathrm{CaCO}_{3}$ & 17.0 & & \\
\hline
\end{tabular}

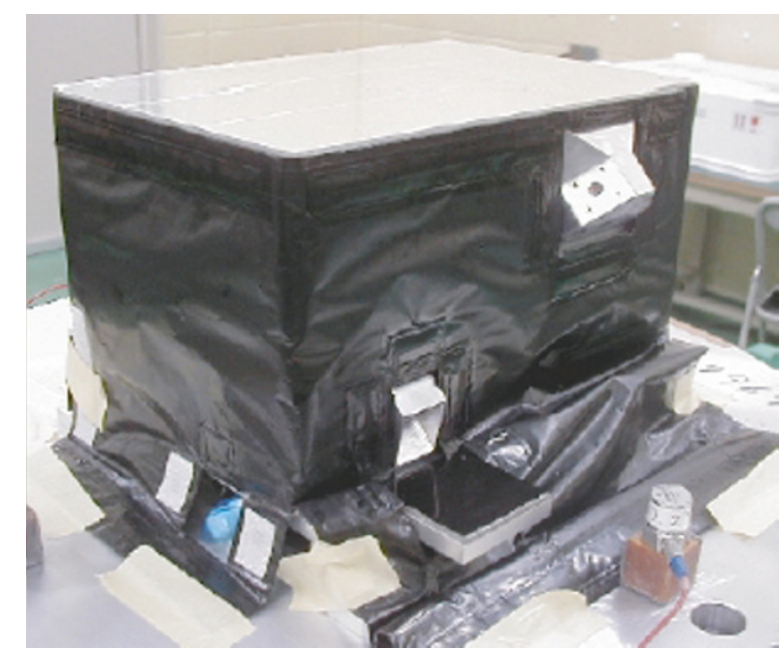

Fig. 2. Photograph of the Solar Monitor (SOL-BC) is shown. A Si-PIN diode based solar X-ray direct monitor (SOL-B) at the upper right position of the SOL-BC and a CCD-based XRF calibrator with a fused sample plate (SOL-C) at the lower center position are united as a single component. The top side is a radiator. SOL-BC is mounted to the top panel of SELENE.

prepared as to represent a lunar rock average. The CCD for SOL-C will measure $\mathrm{X}$-ray emitting from this sample irradiated by the solar $\mathrm{x}$-ray. This measurement not only gives simultaneous monitoring of the solar X-rays, comparable to the direct measurement through SOL-B but is also anticipated to be interpretable as calibrator for the measurement of the XRF-A. The SOL-B and SOL-C are mounted as a united component SOL-BC as shown in Fig. 2.

\subsection{XRS electronics (XRS-E)}

The XRS's detector systems (XRF-A, SOL-B, SOL-C) are controlled by XRS-E which is installed in a independent box holding most of the electronics, including clock generator and correlated double sampler which drives the CCDs through multiplexer.

Two units of XRF-A consisting of four CCDs in each are read-out repeatedly in time sharing manner by a single driver at speed of $125 \mathrm{kHz} /$ pixel. 16 pixels are summed along parallel-transfer direction prior to the readout, resulting all 1024 by 64 effective pixels per a CCD chip to be sampled in every 3 seconds. After the analog-to-digital conversion, the pulse height from each pixel is compared to its running average. Signal from a pixel above the (average + threshold level) is extracted and is written into FIFO memory as x-ray photon event. Low energy cut-off threshold level, is controlled by commands from the ground. Further processes, equipped as a software program working on Hitachi SH-3 CPU are conducted only for these extracted events, which means that XRS is not taking a shot image of

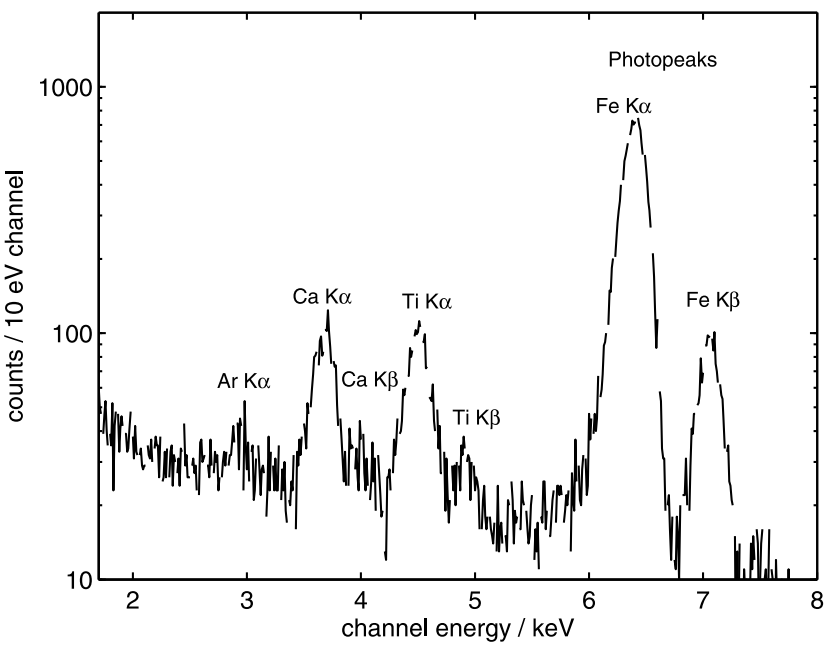

Fig. 3. A typical $\mathrm{x}$-ray spectra as function of photon energy obtained by $\mathrm{XRF}-\mathrm{A}$ at $-40^{\circ} \mathrm{C}$. The specimen used here is also a glassy plate as the one equipped for SOL-C (Table 2), except that $\mathrm{Mn}, \mathrm{Cr}, \mathrm{K}, \mathrm{Na}$ are not included as its composition. The spectrum shows photopeaks for $\mathrm{Fe}, \mathrm{Ti}$, $\mathrm{Ca}$, and Ar. Ar photopeak is detected in absent of expected peaks for $\mathrm{Mg}, \mathrm{Al}$, and $\mathrm{Si}$ due to attenuation of low energy $\mathrm{x}$-ray in the air.

CCD but CCD chips are treated as photon counters. Each of the extracted photon event is sent through telemetry interface using 1553B protocol, directly or after accumulation for 16 seconds into a spectrum of photon energy bins.

Data from Si-PIN photo-diodes are accumulated into 255 channels pulse height histogram every 16 seconds by FPGA controlled hardware.

As shown in Table 1, the total system of the XRS has the mass of $20.7 \mathrm{~kg}$ (XRF-A: $8.7 \mathrm{~kg}$, SOL-BC: $4.0 \mathrm{~kg}$, XRS-E: $7.9 \mathrm{~kg}$ ) and consumes $46.3 \mathrm{~W}$ (power for the active heaters not included) of power for a typical operation. The XRS is allowed to deliver telemetry data to SELENE's data handling system in a rate of 4 kbytes during nominal daytime observation while its rate is reduced to a tenth during nighttime background observation period.

\section{Calibration and Performance of the XRS De- tectors}

We conducted calibration of the XRS data and examined its performance in the laboratory. CCD and Si-PIN photodiode are expected to show good performances under a cooled condition so that the flight instruments were put into liquid nitrogen cooled vacuum chamber or low-temperature chamber.

\subsection{Charge coupled device (CCD)}

One of advantages in using solid state detectors such as CCDs is that its energy resolution is high (full-width at the half maximum FWHM better than $200 \mathrm{eV}$ ) in capable for discriminating adjacent fluorescent lines for our interest including $\mathrm{Mg}(1254 \mathrm{eV}), \mathrm{Al}(1487 \mathrm{eV}), \mathrm{Si}(1740 \mathrm{eV})$, $\mathrm{Ca}(3690 \mathrm{eV}), \mathrm{Ti}(4509 \mathrm{eV})$, and $\mathrm{Fe}(6399 \mathrm{eV})$ in absent of absorption edge filters.

Flight instrument was intensively calibrated in the laboratory before mounted to the SELENE orbiter for pre-flight tests. In the low-temperature chamber, the instruments were set with the specimen placed just in front of each detector. Primary x-rays generated by the $\mathrm{x}$-ray tube irradiate the 


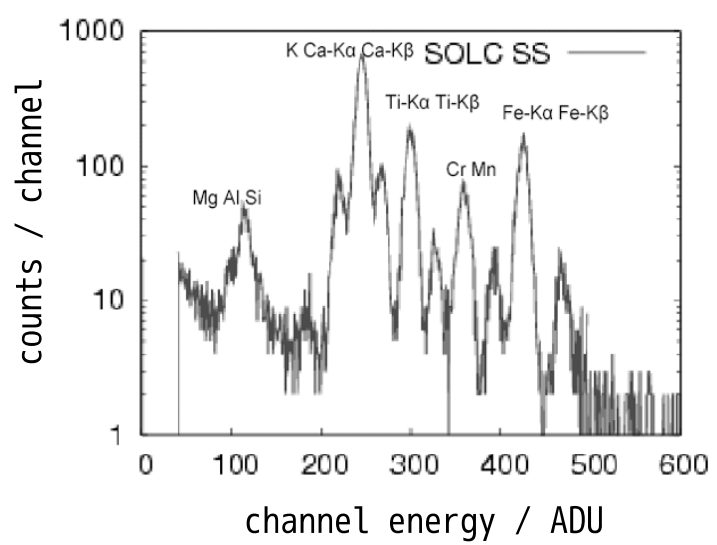

Fig. 4. A typical x-ray spectra as function of photon energy obtained by SOL-C at $-40^{\circ} \mathrm{C}$. The specimen used here is a glassy plate equipped for SOL-C (Table 2), The spectrum shows photopeaks for $\mathrm{Mg}, \mathrm{Si}, \mathrm{K}$, $\mathrm{Ca}, \mathrm{Ti}, \mathrm{Cr}, \mathrm{Mn}, \mathrm{Fe}$. The experiment is performed in vacuum condition.

Table 3. Energy scale and FWHM for each CCD of XRF-A and SOL-C. Note that the energy slope listed here did not show temperature dependence for $-30,-40$ and $-50^{\circ} \mathrm{C}$.

\begin{tabular}{cccc}
\hline chip & $\begin{array}{c}\text { slope } \\
\text { / eV } \cdot \text { ADU }^{-1}\end{array}$ & $\begin{array}{c}\mathrm{FWHM}_{0} \\
/ \mathrm{eV}\end{array}$ & $B$ \\
\hline $\operatorname{ccd} 0$ & $13.38 \pm 0.04$ & 141 & 0.53 \\
$\operatorname{ccd} 1$ & $10.97 \pm 0.03$ & 135 & 0.54 \\
$\operatorname{ccd} 2$ & $12.60 \pm 0.01$ & 160 & 0.50 \\
$\operatorname{ccd} 3$ & $11.45 \pm 0.11$ & 131 & 0.53 \\
$\operatorname{ccd} 4$ & $11.95 \pm 0.06$ & 152 & 0.50 \\
$\operatorname{ccd} 5$ & $10.88 \pm 0.04$ & 155 & 0.49 \\
$\operatorname{ccd} 6$ & $10.93 \pm 0.03$ & 134 & 0.54 \\
$\operatorname{ccd} 7$ & $10.79 \pm 0.07$ & 147 & 0.54 \\
$\operatorname{ccd} 8$ & $11.76 \pm 0.01$ & 154 & 0.50 \\
$\operatorname{ccd} 9$ & $13.64 \pm 0.04$ & 155 & 0.50 \\
$\operatorname{ccd} \mathrm{A}$ & $11.99 \pm 0.02$ & 137 & 0.52 \\
$\operatorname{ccdB}$ & $11.79 \pm 0.04$ & 131 & 0.54 \\
$\operatorname{ccd} \mathrm{C}$ & $10.52 \pm 0.03$ & 164 & 0.49 \\
$\operatorname{ccdD}$ & $9.99 \pm 0.07$ & 188 & 0.44 \\
$\operatorname{ccd} \mathrm{E}$ & $11.75 \pm 0.11$ & 186 & 0.45 \\
$\operatorname{ccd} \mathrm{F}$ & $10.89 \pm 0.04$ & 184 & 0.45 \\
$\operatorname{ccd} S$ & $12.76 \pm 0.05$ & 168 & 0.47 \\
\hline
\end{tabular}

specimen to excite fluorescent X-rays. A typical X-ray spectra obtained with the XRF-A (Fig. 3), and SOL-C (Fig. 4) are shown, in the case of glassy specimen of lunar rock average composition using a tungsten-target x-ray tube.

The slopes of linear fit of the energy scale determined using detected photopeaks for each CCD chip for temperature ranging $-30^{\circ} \mathrm{C}$ to $-50^{\circ} \mathrm{C}$ is listed in second column of Table 3. Energy as function of measured pulse height for the photopeaks is fitted to the relation,

$$
\text { Energy }(\mathrm{eV})=\text { Slope } \times \mathrm{PH}(\mathrm{ADU})+C \text {. }
$$

There exists large diversity in slope value from 9.99 to $13.64 \mathrm{eV}$ between chips. This is due not only to the electronics difference between units but also to the characteristic of the detector itself. These differences in gain between various $\mathrm{CCD}$ chips will be compensated within the ground based analysis before deriving integrated spectrum with data from more than one chip. Resolution of the peak,

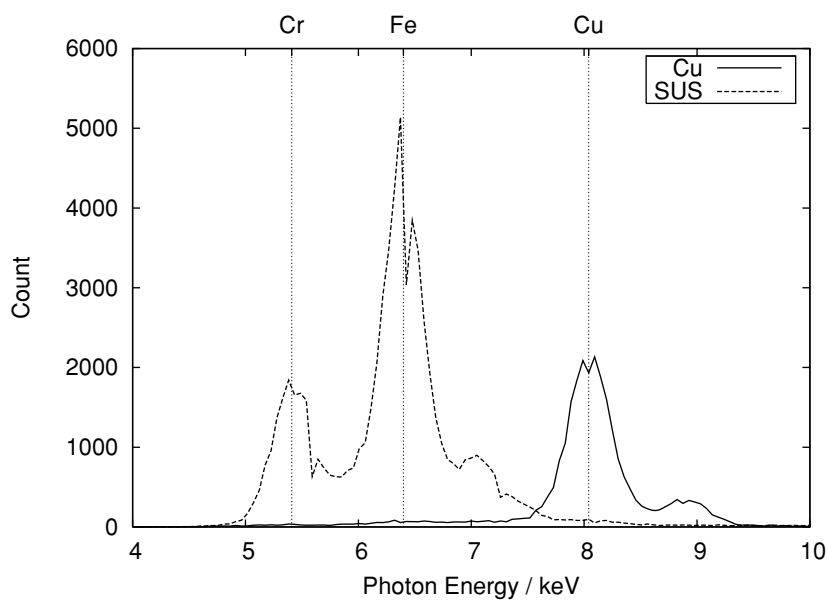

Fig. 5. The X-ray spectra as a function of photon energy obtained by SOL-B at $0^{\circ} \mathrm{C}$. The specimen used here are steel plate (SUS) and copper plate.

Table 4. Energy scale and FWHM for two PIN photo-diodes on SOL-B.

\begin{tabular}{ccc}
\hline chip & $\begin{array}{c}\text { slope } \\
/ \mathrm{eV} \cdot \mathrm{ADU}^{-1}\end{array}$ & $\begin{array}{c}\text { FWHM@5.9 keV } \\
/ \mathrm{eV}\end{array}$ \\
\hline $\operatorname{pin} 0$ & 52.1 & 430 \\
$\operatorname{pin} 1$ & 63.2 & 580
\end{tabular}

values of full-width at the half maximum (FWHM) measured for temperature at $-50^{\circ} \mathrm{C}$ is also listed in Table 3 . The total FWHM resolution on a peak at energy $E$ is a combination of preamplifier noise contribution $\mathrm{FWHM}_{0}$ and the ionization statics and other line-broadening contribution $2 \sqrt{2 \ln 2 B E}$. The total FWHM resolution is given by

$$
\operatorname{FWHM}(E)=\sqrt{\left(\mathrm{FWHM}_{0}\right)^{2}+8 \ln 2 \times B \times E} .
$$

One difficulty of the XRS development is realizing a large detection area by simultaneous driving of $17 \mathrm{CCD}$ chips. Due to the limitation of mass and power budgets, some driving clocks are commonly used between chips so that the CCD driving voltage are not always the best for each chip. However, all the CCD chips had successfully achieved energy resolution better than $200 \mathrm{eV}$ at $5.9 \mathrm{keV}$ after intensive adjustment. Indeed, the CCD C, D, E, and F still shows energy resolution not as good as other chips.

\subsection{Si-PIN diode}

Two Si-PIN diodes on the SOL-B were also calibrated in laboratory. Typical spectra obtained by one of Si-PIN diode at $0^{\circ} \mathrm{C}$ are shown in Fig. 5. Characteristic fluorescence line peaks are for $\mathrm{Cr}$ and $\mathrm{Fe}$ from steel plate (SUS) target and $\mathrm{Cu}$ for copper target are distinguishable. Energy calibration slope and energy resolution at $5.9 \mathrm{KeV}$ for the two SiPIN photo-diodes are tabulated in Table 4. We confirmed that the performance of the SOL-B shows good enough for detecting temporal changes of solar X-ray intensity and spectral profile.

\section{Concluding Remarks}

The X-ray spectrometer (XRS) has been developed to perform quantitative $\mathrm{x}$-ray spectroscopic observation of the lunar surface in SELENE mission. The XRS has undergone 
various performance evaluation tests and launched to the moon in the summer of 2007. Usage of 16 CCD chips with the adoption of ultra-thin beryllium optical light-tight window has allowed large effective area to collect the $\mathrm{x}$-ray emitting from the lunar surface in fairly high energy resolution. Presented here are calibration results which would play a key role in analyzing the actual measurement while in orbit of the moon. Currently calibrational measurements are carefully reexamined as well as the procedures in reducing elemental composition distribution of the moon from the XRS observation.

With the energy resolution presented in this study, we performed a numerical series of calculation for lunar $\mathrm{x}$-ray fluorescence emission and discussed the necessary integration time for achieving both sufficiently high signal to background ratio and the along-the-track spatial resolution under assumed solar x-ray conditions. These measurements not only depend on elemental composition of the lunar surface but also are strongly reflected by the intensities and spectral profiles of incident solar x-rays. Solar activity is expected to be at near minimum to middle level during the SELENE nominal operation period where it will bring counting statistics a limiting factor of observation. Anticipated solar output for this period in our modeling is approximately B1 solar flare level, with some higher solar flare levels such as $\mathrm{M}$ for only a limited time of duration. Taking these into account, we still expect to make a quantitative observation with $20 \mathrm{~km}$ spatial resolution, both in cross-the-track and along-the-track direction with integration time of around 16 seconds for $\mathrm{Mg}, \mathrm{Al}, \mathrm{Si}$, and possibly $\mathrm{Ca}$, especially in equatorial region, while elements such as $\mathrm{Ti}$ and $\mathrm{Fe}$ in this spatial resolution will be limited to locations where solar activity happens to increase. These results are discussed and presented in the companion paper (Ogawa et al., 2008).

Acknowledgments. The XRS instrument was manufactured by Meisei Electric Co., Ltd., in Japan. The SELENE (Kaguya) mission is organized by the Institute of Space and Astronautical Science of the Japan Aerospace Exploration Agency, in collaboration with earth and planetary science community of Japan and overseas.

\section{References}

Adler, I. J. and J. Trombka, Orbital chemistry: lunar surface analysis from $\mathrm{x}$-ray and gamma-ray remote sensing experiments, Phys. Chem. Earth, 10, 17-43, 1977 .

Adler, I. J., J. Trombka, J. Gerard, P. Lowman, R. Lamothe, R. Schmadebeck, H. Blodget, E. Eller, L. Yin, P. Gorenstein, and P. Bjorkholm, Apollo 15 geochemical X-ray fluorescence experiment: Preliminary report, Science, 175, 436-440, 1972.

Benkhoff, J., MPO_-The BepiColombo Mercury Planetary Orbiter, Lunar Planet. Sci., XXXVIII, 2169, 2007.

Bhandari, N., Chandrayaan-1: Science Goals, J. Earth Syst. Sci., 114, 701$709,2005$.

Bielefeld, M., C. Ander, E. Eliason, P. Clark, I. Adler, and J. Trombka, Imaging of the lunar surface chemistry from orbital X-ray data, Proc. Lunar Sci. Conf. 8th, 901-908, 1977.

Clark, P. E. and B. R. Hawke, Compositional Variations in the Hadley Apennine Region, Lunar Planet. Sci., XXII, 148-150, 1981.

Clark, P. E., C. G. Andre, I. Adler, and E. Eliason, A new color correlation method applied to XRF Al/Si ratios and other lunar remote sensing data, Proc. Lunar Sci. Conf. 9th, 3015-3027, 1978.
Gold, R. E., S. C. Solomon, R. L. McNutt, Jr., A. G. Santo, J. B. Abshire, M. H. Acuña, R. S. Afzal, B. J. Anderson, G. B. Andrews, P. D. Bedini, J. Cain, A. F. Cheng, L. G. Evans, W. C. Feldman, R. B. Follas, G. Gloeckler, J. O. Goldsten, S. E. Hawkins III, N. R. Izenberg, S. E. Jaskulek, E. A. Ketchum, M. R. Lankton, D. A. Lohr, B. H. Mauka, W. E. McClintock, S. L. Murchie, C. E. Schlemm II, D. E. Smith, R. D. Starr, and T. H. Zurbuchend, The MESSENGER mission to Mercury: scientific payload, Planet. Space Sci., 49, 1467-1479, 2001.

Grande, M., The D-CIXS X-ray spectrometer on ESA's SMART-1 mission to the Moon, Earth Moon Planets., 85, 143-152, 2001.

Grande, M., S. K. Dunkin, and B. Kellett, Opportunities for X-ray remote sensing at Mercury, Planet. Space Sci., 49, 1553-1559, 2001.

Grande, M., B. J. Kellett, C. Howe, C. H. Perry, B. Swinyard, S. Dunkin, J. Houvelin, L. Alha, L. C. D'Uston, S. Maurice, O. Gasnault, S. Couturier-Doux, S. Barabash, K. H. Joy, I. A. Crawford, D. Lawrence, V. Fernandes, I. Casanova, M. Wieczorek, N. Thomas, U. Mall, B. Foing, D. Hughes, H. Alleyne, S. Russel, M. Grady, R. Lundin, D. Baker, C. D. Murray, J. Guest, and A. Christou, The D-CIX X-ray spectrometer on the SMART-1 mission to the Moon-First results, Planet. Space Sci., 55, 494-502, 2007.

Kato, M., S. Sasaki, K. Tanaka, Y. Iijima, and Y. Takizawa, The Japanese lunar mission SELENE: Science goals and present status, Adv. Space Res., doi:10.1016/j.asr.2007.03.049, 2007 (in press).

Kellett, B. J., M. Grande, and the D-CIXS Science Team, X-ray fluorescence observations of the Moon-highlights from the first year of observations from D-CIXS on SMART-1, Lunar Planet. Sci., XXXVII, 1897, 2006.

Miyaguchi, K., H. Suzuki, J. Dezaki, and K. Yamamoto, CCD developed for scientific application by Hamamatsu, Nucl. Instr. and Meth. A, 436, 24-31, 1999.

Ogawa, K., T. Okada, K. Shirai, and M. Kato, Numerical estimation of lunar X-ray emission for X-ray spectrometer onboard SELENE, Earth Planets Space, 60, this issue, 283-292, 2008.

Okada, T., M. Kato, A. Fujimura, H. Tsunemi, and S. Kitamoto, X-ray fluorescence spectrometry with the SELENE orbiter, Adv. Space Res., 23, 1833-1836, 1999.

Okada, T., M. Kato, A. Fujimura, H. Tsunemi, and S. Kitamoto, X-ray fluorescence spectrometer onboard Muses-C, Adv. Space Res., 25, 345$348,2000$.

Okada, T., M. Kato, Y. Yamashita, K. Shirai, Y. Yamamoto, T. Matsuda, H. Tsunemi, and S. Kitamoto, Lunar X-ray spectrometer experiment on the SELENE mission, Adv. Space Res., 30(8), 1909-1914, 2002.

Okada, T., K. Shirai, Y. Yamamoto, T. Arai, K. Ogawa, K. Hosono, and M. Kato, X-ray fluorescence spectrometry of asteroid Itokawa by Hayabusa, Science, 312, 1338-1341, 2006a.

Okada, T., K. Shirai, Y. Yamamoto, T. Arai, K. Ogawa, K. Hosono, and M. Kato, Instrumentation and observations of the X-ray spectrometer onboard Hayabusa, in Advances in Geosciences, Vol.3: Planetary Science $(P S)$, edited by A. Bhardwaj, World Scientific, Singapore, pp. 231-240, $2006 b$.

Sasaki, S., Y. Iijima, K. Tanaka, M. Kato, M. Hashimoto, H. Mizutani, and Y. Takizawa, The SELENE mission: Goals and status, Adv. Space Res., 31, 2335-2340, 2003.

Sun, H., S. Dai, J. Yang, J. Wu, and J. Jiang, Scientific objectives and payloads of ChangE-1 lunar satellite, J. Earth Syst. Sci., 114, 789-794, 2005.

Trombka, J. I., S. W. Squyres, J. Brückner, W. V. Boynton, R. C. Reedy, T. J. McCoy, P. Gorenstein, L. G. Evans, J. R. Arnold, R. D. Starr, L. R. Nittler, M. E. Murphy, I. Mikheeva, R. L. McNutt Jr., T. P. McClanahan, E. McCartney, J. O. Goldsten, R. E. Gold, S. R. Floyd, P. E. Clark, T. H. Burbine, J. S. Bhangoo, S. H. Bailey, and M. Petaev, The Elemental Composition of Asteroid 433 Eros: Results of the NEAR-Shoemaker X-ray Spectrometer, Science, 289(5487), 2101-2105, 2000.

Yamamoto, Y., T. Okada, H. Shiraishi, K. Shirai, T. Arai, K. Ogawa, K. Hosono, M. Arakawa, and M. Kato, Current status of X-ray spectrometer development in the SELENE project, Adv. Space Res., 2007 (in press).

K. Shirai (e-mail: shirai@planeta.sci.isas.jaxa.jp), T. Okada, Y. Yamamoto, T. Arai, K. Ogawa, H. Shiraishi, M. Iwasaki, M. Arakawa, M. Grande, and M. Kato 